\title{
Burn-up calculation of the neutronic and safety parameters of thorium-uranium mixed oxide fuel cycle in a Westinghouse small modular reactor
}

\author{
Edwin H. Uguru ${ }^{1,2}$ () | Siti F. Abdul Sani ${ }^{1}$ | Mayeen U. Khandaker ${ }^{3}$ | \\ Mohamad H. Rabir ${ }^{4}$ ( ) | Julia A. Karim ${ }^{4}$ | Daniel U. Onah ${ }^{2}$ | David A. Bradley,5
}

${ }^{1}$ Department of Physics, University of Malaya, Kuala Lumpur, Malaysia

${ }^{2}$ Department of Industrial Physics, Ebonyi State University, Abakaliki, Nigeria

${ }^{3}$ Centre for Biomedical Physics, School of Healthcare and Medical Sciences, Sunway University, Bandar Sunway, Malaysia

${ }^{4}$ Nuclear and Reactor Physics Section, Nuclear Technology Center, Technical Support Division, Malaysian Nuclear Agency, Kajang, Malaysia

${ }^{5}$ Centre for Nuclear and Radiation Physics (CNRP), Department of Physics,

University of Surrey, Guildford, UK

\section{Correspondence}

Edwin H. Uguru and Siti F. Abdul Sani, Department of Physics, University of Malaya, Kuala Lumpur 50603, Malaysia. Email: ugurueddy2008@yahoo.com (E.H. Uguru) and s.fairus@um.edu.my (S.F.A. Sani)

\section{Funding information}

Universiti Malaya, Grant/Award Number: GPF036B-2018

\section{Summary}

Thorium fuel is presently a globally known future nuclear fuel alternative, having good neutronic, physical and chemical properties in addition to its spent nuclear fuel characteristic proliferation resistance. This research focused on the neutronic and safety parameters of thorium-uranium mixed oxide fuel cycle, utilising three fissile enrichment zones, a departure from the conventional single enrichment. The aim was to determine the range of three fissile zones adequate for thoriumuranium fuel cycle; investigating the performance efficiency of the fuel neutronic and inherent safety parameters in response to temperature differentials, which determines the viability of the fuel and core composition. Use was made of the MCNPX 2.7 code integrated with the CINDER90 fuel depletion code for steadystate and burn-up calculations. The $k_{\text {eff, }}$ moderator temperature coefficient (MTC) and fuel temperature coefficient (FTC) of reactivity are affected by the range of fissile enrichment and fuel temperature which decreased with their respective increases. The MTC for all the moderator temperatures was within 0 to $-40 \mathrm{pcm} / \mathrm{K}$ design value for $\mathrm{UO}_{2}$ fuel. Similarly, the FTC was within -3.5 to -1 $\mathrm{pcm} / \mathrm{K}$ design value for all the fuel temperatures except after 2000 days, where a positive reactivity feedback was introduced. At $\sim 86 \mathrm{MWd} / \mathrm{kgHM}$ single discharge burn-up, the result shows that $\sim 90 \%$ of the initial fissile load was utilised for energy production at the normal reactor operating temperature $(600 \mathrm{~K})$ with a slight reduction at higher fuel temperature. The total fissile inventory ratio (FIR), ${ }^{233} \mathrm{U} / \mathrm{kg}^{232} \mathrm{Th}$ and ${ }^{239} \mathrm{Pu} / \mathrm{kg}_{-}{ }^{238} \mathrm{U}$ inventory ratios were significantly large and increased with burn-up. It is remarkable that the FIR and the ${ }^{233} \mathrm{U} / \mathrm{kg}^{232} \mathrm{Th}$ inventory ratio did not reach conversion equilibrium until exit burn-up. The large percentage fuel utilisation supports the advantage of fissile enrichment zoning in a thermal nuclear reactor core, making the chosen novel three fissile enrichment zones for thorium-uranium fuel cycle reliable.

\section{K E Y W O R D S}

coefficient of reactivity, fissile enrichment zones, neutronic, safety parameters, small modular reactor, thorium fuel cycle 